\title{
PRESUPUESTOS DE EGRESOS CON PERSPECTIVA DE GÉNERO ${ }^{1}$
}

\section{Andrés Miranda Guerrero}

\begin{abstract}
Resumen
El presente trabajo tiene por objeto enfatizar la importancia de la realización de Presupuestos de Egresos con Perspectiva de Género, se revisa el marco jurídico en México, en correlación con la normatividad del estado de Sonora, desde el fundamento constitucional hasta las leyes secundarias, haciendo alusión a los planes de desarrollo de ambos órdenes de gobierno.Posteriormente, se aborda el marco conceptual, donde se define en que consiste el presupuesto público, y su análisis con la visión de la perspectiva de género en un marco de igualdad entre mujeres y hombres. Finalmente la parte conclusiva del trabajo, argumentando la transparencia y la rendición de cuentas en la implementación de los presupuestos de egresos con criterio de género, considerados en todo el gasto público-
\end{abstract}

Palabras Clave: Gobierno, Presupuesto, Género, Igualdad y Equidad.

\section{Introducción}

México enfrenta un proceso de cambio profundo -obligado y necesario- de su agenda y de su forma de plantear las políticas públicas nacionales para incorporar la perspectiva de género, no sólo para atender las demandas derivadas de la creciente participación de las mujeres en el mercado laboral y en los puestos de tomas de decisiones, sino como un imperativo para la consolidación de sus sistemas políticos basados en la equidad de acceso de hombres y mujeres a las oportunidades y beneficios del desarrollo.

\footnotetext{
${ }^{1}$ Ensayo realizado para la asignatura Adecuación del Estado y la Administración Pública en México del Programa de Doctorado en Administración Pública, ISAPAC
} 
Es por ello, que una fase importante de esa agenda de cambio lo constituye el diseño, la formulación y la programación de las actividades gubernamentales a partir de un presupuesto de egresos que incluye los criterios de género aplicables para todo el gasto público.

Es indudable, que los presupuestos sensibles al género no sólo dedican mayores $y$ crecientes recursos en beneficio de las mujeres, sino que son planteados íntegramente a partir de valorar el impacto diferenciado que tiene el ejercicio del gasto sobre mujeres y hombres, sus necesidades y demandas.

Ante tal situación, el presente trabajo, parte necesariamente de un entorno general del plano nacional, para posteriormente ir paulatinamente abordando aspectos concernientes al ámbito estatal.

En ese contexto, la equidad de género es un tema que ha cobrado importancia en el espacio de la política pública en los últimos años. Tanto en el espacio federal como en el local, se han realizado esfuerzos por aplicar políticas específicas y crear instituciones de gobierno dedicadas a resolver los problemas relacionados con la desigualdad entre los géneros.

Cabe advertir, que la incorporación de la perspectiva de género en los presupuestos de egresos es un ejercicio relativamente reciente en México.

\section{Marco Normativo}

"La igualdad de género es un principio constitucional que estipula que hombres y mujeres son iguales ante la Ley", lo que significa que todas las personas, sin distingo alguno tenemos los mismos derechos y deberes frente al Estado y la sociedad en su conjunto.

Nuestro derecho se basa en tres tipos de igualdad: la absoluta, relativa y normativa. La primera se refiere a que todo hombre y mujer es en la misma medida sujeto de derecho; la segunda se sustenta en el hecho de que dependiendo del estado de las cosas, las personas en situaciones análogas deben 
recibir el mismo trato; mientras que la última, en contrario de las anteriores, busca que la norma aproveche por igual, a todos los individuos, siendo el sistema jurídico el que se adapta a las personas ${ }^{2}$.

Desde el 2006 nuestro país cuenta con la Ley General para la Igualdad de Género entre Mujeres y Hombres, la cual establece las atribuciones de los tres órdenes de gobierno en la aplicación coordinada de la política nacional de igualdad, siendo sus objetivos los siguientes: la vida económica, la participación y representación política, acceso y pleno disfrute de los derechos sociales, en la vida civil y en la vida cultural ${ }^{3}$.

En nuestro estado, esta Ley General se armonizó en el 2008, dando creación a la Ley para la Igualdad entre Mujeres y Hombres en el Estado de Sonora.

Estableciendo en el artículo 13, fracción VII, que al Ejecutivo del Estado, corresponde incorporar en los proyectos de presupuesto de egresos del estado, la asignación de recursos para el cumplimiento de la política estatal en materia de igualdad. Además, en la fracción VIII, fortalecer los mecanismos, institucionales de promoción y procuración de la igualdad entre mujeres y hombres, mediante las instancias administrativas que se ocupen del adelanto de las mujeres en el estado. En nuestro país, desde que se aprobó el artículo cuarto de la Carta Magna, después de cuarenta años, la igualdad entre hombres y mujeres, en los órdenes de gobierno federal y estatal, se critica que el desarrollo normativo de la constitución no ha demostrado un verdadero y real objetivo por parte de los poderes públicos de conseguir que el principio de igualdad sea una realidad.

Ahora bien, respecto a los Planes Nacionales (2013-2018) y Estatal (2016-2021), de Desarrollo, por primera vez contienen una estrategia que incorpora transversalmente la igualdad de género y el empoderamiento de las mujeres, y mandatan la incorporación de la perspectiva de género en las políticas públicas, programas, proyectos e instrumentos compensatorios de la administración pública, en ambos órdenes de gobierno.

\footnotetext{
${ }^{2}$ Reyes R. Venustiano, "El Principio Jurídico de Igualdad”, Jurídica, México, Departamento de Derecho de la U. Iberoamericana, 2003.

${ }^{3}$ www.puntogénero.inmujeres.gob.mx
} 
Dentro del marco normativo para elaborar presupuestos de egresos con perspectiva de género, también se encuentran las Leyes de Planeación tanto federal como estatal. Así como la Ley Federal de Presupuesto y de Responsabilidad Hacendaria y la Ley del Presupuesto de Egresos y Gasto Público estatal.

\section{Marco Conceptual}

Una vez analizada la normatividad federal y estatal en relación a los presupuestos de egresos con perspectiva de género, he considerado desarrollar el tema hacia la parte conceptual, misma que nos ayudará a la comprensión, aún más, de la temática en comento.

Al respecto, podemos concretar que a los presupuestos públicos con perspectiva de género también se les denomina sensibles al género, con enfoque de género y pro-equidad de género. Este tipo de presupuesto público ha sido definido de diversas formas.

Es por ello, que hablar de un presupuesto sensible al género, o de presupuestos para las mujeres, no hace referencia a un presupuesto aparte para atender específicamente las necesidades de las mujeres. En realidad analizar los presupuestos públicos a través de la visión de la perspectiva de género, busca abrir procesos que faciliten una evaluación de los impactos que el gasto público tiene en los géneros.

Como tal, es un esfuerzo por desagregar el presupuesto del gobierno partiendo del impacto que tiene en mujeres y hombres, a la vez de identificar los beneficios diferenciados que ofrece a distintos grupos de mujeres y de hombres dentro del contexto social, económico, cultural y político prevaleciendo para cada uno de éstos.

Esta desagregación es importante, debido a que al contrario de lo que suponen las principales corrientes de la economía, los presupuestos públicos no son neutrales al género. Todo gasto público tiene algún impacto, y éste no es necesariamente 
igual para mujeres y hombres. Ante ello, ignorar este impacto diferenciado, así como las implicaciones que debería tener para el diseño de las políticas públicas y la asignación de recursos, no habla de cierta neutralidad, sino de desconocimiento de la diferencia de género.

Por eso, en la manera en que se formulan los presupuestos públicos generalmente ignora los roles, responsabilidades y capacidades diferentes y socialmente determinadas que predominan para mujeres y hombres, niñas y niños. Estas diferencias están estructuradas de tal manera que dejan a las mujeres y a las niñas en posiciones de desventaja frente a los hombres, con menos recursos económicos, sociales y poder político. Por tanto, es indispensable entender estos impactos diferenciados para la estructura de políticas públicas que parten de condiciones reales y, de esta manera, confluyen hacia soluciones reales.

Se puede considerar, que un proceso presupuestario sensible al género debe integrar la transversalidad a cada uno de los aspectos del gasto, promover la participación activa de las mujeres, evaluar el impacto del gasto de la perspectiva de género, y contribuir al que uso y la asignación de recursos estén encaminados hacía la equidad ${ }^{4}$.

Por otro lado, los presupuestos pro-equidad de género, están en un proceso de construcción, es decir, continuamente se diseñan nuevas estrategias, métodos y herramientas para lograr la inclusión de las necesidades prácticas y estratégicas de las mujeres en los presupuestos públicos. Sin duda, que la parte del gasto ha sido la más desarrollada.

A la interrogante de ¿cómo se elaboran los presupuestos públicos con perspectiva de género?, remite a la revisión de las propuestas metodológicas, las cuales han ido evolucionando a la par con las transformaciones en los sistemas presupuestarios y en los mismos presupuestos públicos.

Es por eso, que cuando se habla de perspectiva de género, se aluden a una herramienta conceptual que busca mostrar que las diferencias entre mujeres y

\footnotetext{
${ }^{4}$ Rusimbi, Mary, Debbie Budlender, Septiembre 2000; citado por Helena Hofbaurer, FUNDAR, 2008.
} 
hombres se dan, más que por su definición biológica, por las diferencias culturales asignadas a los seres humanos.

En suma, la importancia de la aplicación de la perspectiva de género en los estudios sociales radica en las posibilidades que brinda para comprender como se produce la discriminación hacia las mujeres y las vías para transformarla.

Por otra parte, en cuanto a la experiencia federal en la asignación de recursos para la igualdad de género, a partir de 2008, el Decreto del Presupuesto de Egresos de la Federación incorpora un anexo específico donde se etiquetan recursos para la igualdad entre mujeres y hombres. Ahí se identifican programas para la atención de necesidades básicas y estadísticas de las mujeres, así como el desarrollo de acciones interinstitucionales, para disminuir las brechas de desigualdad de género y garantizar plenamente los derechos humanos de las mujeres y las niñas.

En el ámbito estatal, el Gobierno del Estado de Sonora, impulsa acciones rumbo a la igualdad sustantiva entre hombres y mujeres por lo que en la iniciativa de presupuesto de egresos se contempla con perspectiva de género; con el objeto de dar cumplimiento a lo establecido en el Plan Estatal de Desarrollo (2015-2021), así como el programa transversal de igualdad de género de sonora.

El presupuesto de egresos es parte de la política pública en el sentido de que su diseño y ejecución es una acción del Estado. Es mediante el presupuesto de egresos que las políticas públicas dejan de ser "promesas de papel" y se transforman en acciones concretas. Los presupuestos con equidad de género dirigen su atención hacía la política económica porque se centran en el presupuesto, sin embargo, son parte de la estrategia general para institucionalizar la perspectiva de género en la administración pública. 


\section{Conclusiones}

Es de primordial importancia de incorporar la visión de la perspectiva de género en los presentes y futuros presupuestos de egresos de los tres órdenes de gobierno. Por ello, la necesidad imperiosa de una agenda pública y de gobierno que considere la transparencia y la rendición de cuentas, en el diseño, la formulación y la programación, para la implementación de presupuesto de egresos con criterios de género aplicables a todo el gasto público.

Como se puede observar, el gobierno ha epresado su compromiso con los objetivos de igualdad de género y con la transversalización de las políticas con la perspectiva de género, sin embargo, con frecuencia existe una brecha entre las políticas públicas y los modos en los cuales los gobiernos recaudan y gastan los recursos públicos.

Por ello, al analizar el marco jurídico normativo nos damos cuenta de que hemos avanzado en crear los mecanismos idóneos que permiten la coordinación, para hacer realidad ese enfoque de la perspectiva de género, desde el plano constitucional, legal y desde los planes y programas de desarrollo tanto federal como estatal.

Es indudable, que el presupuesto público (egresos) tiene un gran impacto sobre las condiciones de vida de las personas, reduce, aumenta, o deja igual las desigualdades existentes entre mujeres y hombres, por lo tanto, es necesario analizar, en todas la fases del presupuesto el impacto diferenciado entre mujeres y hombres a lo largo de las distintas etapas de su implementación e instrumentación.

En consecuencia se sostiene que la integración de un marco de presupuestación con énfasis en la perspectiva de género requiere de exámenes más exhaustivos; 
debido a que la incorporación de la perspectiva de género en el análisis presupuestal traslada nuevos valores al círculo presupuestario, de esa manera representa un nicho de desafíos y oportunidades para la medición del desempeño de la administración pública.

\section{Referencias Bibliográficas}

Arellano Gault, David y Gabriel Purón. 2004, "México. Reforma al Sistema Presupuestal: Una Reforma Atrapada por las Inercias". Editorial Porrúa. México.

Helena Hofbaurer y Claudia Vinay. FUNDAR. Centro de Análisis e Investigación. Presupuestos Sensibles al Género. México. 2008.

INMUJERES. Instituto Nacional de las Mujeres. Entidad de las Nacionales Unidas para la Igualdad de Género. ONU Mujeres. 2004.

Página web: www.genero.inmujeres.gob.mx

Página web: www.shcp.gob.mx

Página web: www.sonora.gob.mx

Reyes R. Venustiano. "El Principio Jurídico de Igualad". Jurídica. México. Departamento de Derecho de la Universidad Iberoamericana. 2003.

\section{Legislación Consultada}

Constitución Local del Estado Libre y Soberano de Sonora.

Constitución Política de los Estados Unidos Mexicanos.

Ley de Presupuesto de Egresos y Gasto Público Estatal.

Ley Federal de Presupuesto y Responsabilidad Hacendiaria.

Ley General para la Igualdad de Género entre Mujeres y Hombres.

Ley para la Igualdad entre Mujeres y Hombres de Sonora.

Leyes de Planeación tanto Federal como Estatal.

Plan Estatal de Desarrollo (2015-2021).

Plan Nacional de Desarrollo (2013-2018). 